\title{
ANALYTIC HIERARCHY PROCESS OF PILOT ECO-DESIGN FRAMEWORK
}

\author{
Francesco Costantino* \\ Giulio Di Gravio \\ Massimo Tronci \\ Department of Mechanical and Aerospace Engineering \\ University of Rome "La Sapienza" \\ Rome, Italy \\ E-mail: francesco.costantino@uniroma1.it \\ giulio.digravio@uniroma1.it \\ massimo.tronci@uniroma1.it
}

\begin{abstract}
Nowadays, industrial engineers have to consider many different environmental aspects and requirements in designing new products. Furthermore, an always stronger reduction of energy and raw materials consumption is expected to generate savings and help recycling, mainly due to a recent increase in the number of international regulations and standards along with customer sensitivity.

As many solutions can be generally adopted during the design stage, a systematic framework can be helpful in considering and evaluating these opportunities to drive organizations in balancing benefits and costs and defining their own priorities.

The paper starts from the PILOT reference model of the Technische Universität of Wien, a qualitative tool that combines principles of Product Modeling, Life Cycle Assessment, Eco-Design tasks, Product Improvement and Environmental Communication as a guide to select among different interventions. An Analytic Hierarchy Process can so be implemented on this approach to quickly identify, in a wide range of possibilities, priorities that grant best environmental performances. The model was tested in the industry of pneumatic and results were used as a validation of the new methodology.
\end{abstract}

Keywords: Eco-Design, environmental improvement, product design

\section{Introduction and background of the research}

Environmentally Conscious Design (or Eco-Design) represents one of the most widespread and effective approaches to product development that can help industries answering the ever growing environmental and social pressure, increasing, at the same time, corporate responsibility. In such a context, one of the most considerable problems concerns the need of integrating environmental impacts and requirements of mandatory (or voluntary) regulations in the product innovation processes. Furthermore, each stage of the products' life cycle has a different effect on the environment, which may be low or significant, of a shortterm or long-term duration.

Eco-efficiency strategies focus on maintaining or increasing the value of economic output while simultaneously decreasing the impact of economic activity upon ecological systems [1]. The relations between Life Cycle Assessment and Eco-Design were studied to identify frameworks, methodologies and tools to support organizations during the design process ([1], [2]). The high complexity in combining LCA [3] and Eco-Design limit the application of these methodologies, especially in small and mediumsized enterprises [4], mainly due to:

- the extension of the whole life cycle where, for each activity, it's to consider not only the disposal

\footnotetext{
${ }^{*}$ Corresponding author
} 
stage but also the production, distribution and use stages [5];

- all product's characteristics, such as safety, aesthetics, costs, etc. have to be integrated and harmonized with environmental factors;

- benefits of applying Eco-Design principles for manufacturers, consumers and the society, are not easy to measure [6] and generally nor evident;

- every design alternative can have a positive, negative or neutral correlation with the possibility to implement others solutions.

Many authors are using AHP/ANP to evaluate priorities of intervention in Eco-Design process, in particular to evaluate alternatives of innovation. Many experiences took in consideration absolute impacts [7, 8] or 'improvement ratios' between new and old or existing products [9], identify the degree of importance of each Eco-Design measure in specific industries [10,11] or assess environmental risks [13]. The paper proposes e complete framework in this very relevant research field, starting from the EcoDesign Pilot project by Wimmer [14], making the most of all the strengths of a complete, sound and verified reference model.

\section{Methodology}

PILOT is an acronym that stands for "Product Innovation Learning and Optimization Tool", recognized as one of the best Eco-Design frameworks in literature. PILOT, a collection of guidelines and checklists to fast identify improvement areas, opportunities and indicators, was developed to communicate and train designers in addressing product innovation or re-design (i.e. the improvement of an already existing product).

Information in PILOT are public, well organized and classified in basic types of products according to the importance of the different life cycle stages: "Raw Material Intensive", "Manufacture Intensive", "Transportation Intensive", "Use Intensive" and "Disposal Intensive". This allows to apply the framework in different fields, just moving into the different categories, reaching specific suggestions.

An example of application is the optimization of the packaging of a small flowerpot, bubble wrapped with a foil of polyethylene and put in a cardboard box. The requirements that have to be fitted are:

- flowerpots in this size should be reusable because the collection for recycling is laborious and expensive;

- packaging is a protection against breaking and so it should be lightweight and stackable.

The checklists of the PILOT present a set of improvement areas where the user is asked to evaluate a level of relevance and an actual degree of fulfilment. Improvement areas can so be prioritized to suggest best alternatives and guide detailed analysis. To give an example of the improvement assessed in this studies, it's possible to cite the description of the "Preferably use single material components and/or reduce number of different types of material" principle:

If one succeeds to manufacture each of the individual components of a product of one single material this constitutes an essential contribution to closed materials cycles (recycling). This goal can certainly not be realized in all cases for reasons of function, strength, etc. Nevertheless, single material components should be preferred wherever possible.

At the end of the process, the packaging changed in terms of functional principle: the cardboard is now cut to host the flowerpot in a hole, fold to protect and block it by a tongue. The amount of material is halved, still sufficient to protect the flowerpot from damages, using only one type of material as the flower seeds are in a paper bag with no need of the bubble wrap and the plastic bag. The implementation of the measures represents a saving in fossil resources and, additionally, the material separation for recycling after use is no more necessary. Furthermore, the packaging itself can be used for promotion, 
printing the paper slips. This approach starts from the study of a product and guides to identify improvements, but what about if more environmental opportunities are available?

Starting from the PILOT architecture, a first general AHP model was built to lead designers towards the most significant environmental opportunities, considering as alternatives the potentialities and impacts of every available improvement.

The AHP goal is to identify the best alternative of environmental improvement. Five criteria are derived from the characteristics of the product, considering its impacts in the life-cycle phases: Materials, Production, Transport, Use and Disposal. Every criteria is linked to some of the 118 Eco-Design improvement areas of the PILOT framework, as presented in Figure 1.

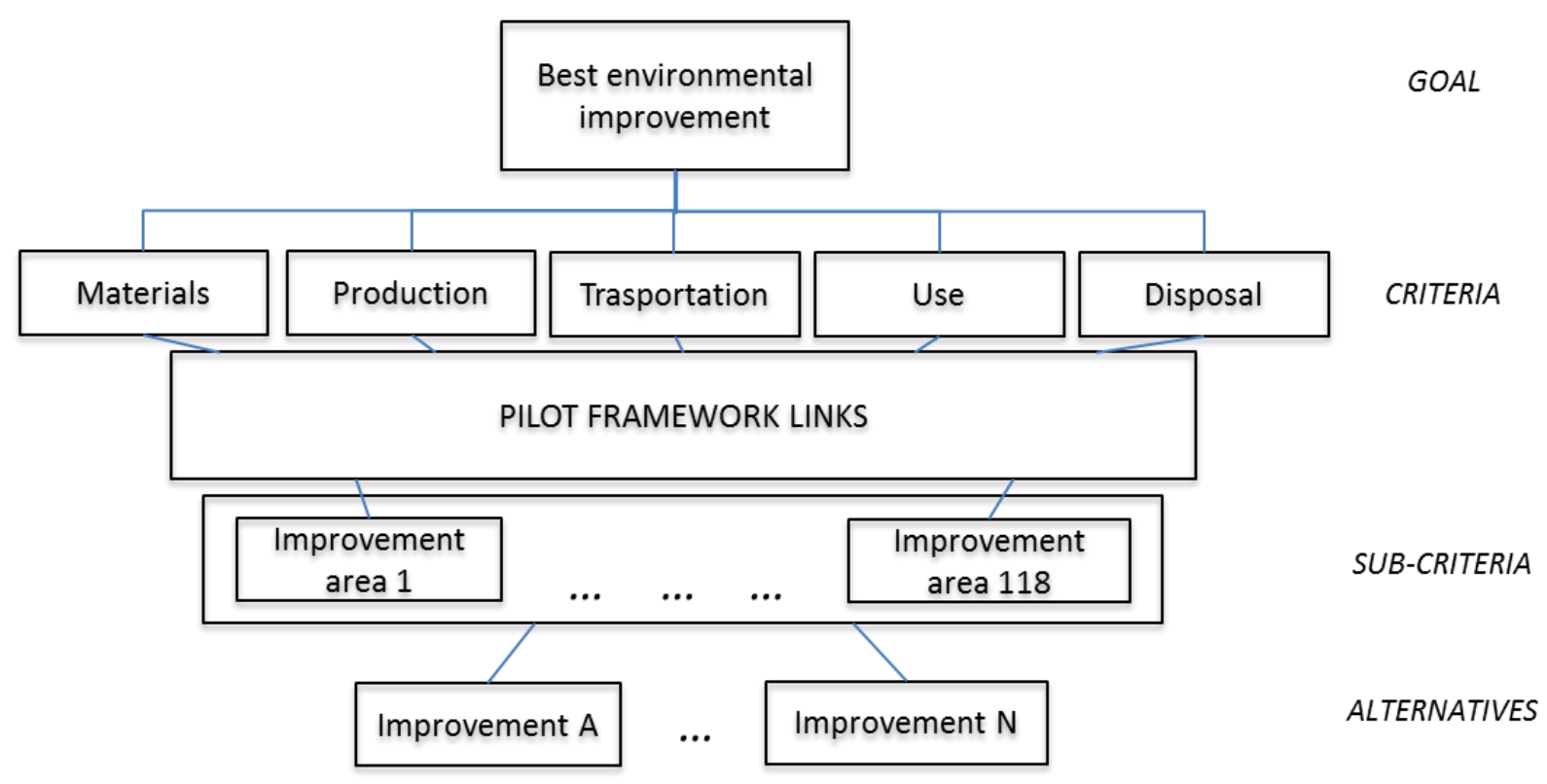

Figure 1. AHP model of PILOT Eco-design framework.

\section{Case study}

A real case application shows how the methodology works and achieves results. The experience is about production of tires, a "Use Intensive" product due to the environmental impact of tire friction on fuel consumption. Actually, a study of tire's life cycle assessment (LCA) was conducted under Japan Rubber Manufacturers Association, revealing that the usage stage accounts for more than $85 \%$ of total emissions of $\mathrm{CO}_{2}$ in an entire life cycle of a common tire [15]. The European Association for Tyre Recycling reports on its website that every year more than 2.600.000 tons of used tires go to disposal phase. Based on data compiled by the Rubber Manufacturers Association (RMA), it is estimated that 275 million tires remained in stockpiles across the United States in 2003 and that approximately 290 million new scrap tires are generated each year [16]. Furthermore the negative effects on water contamination and air emissions due to scrap tires combustion or disposal are well known ${ }^{1}$. Consequently, an application of the proposed AHP model on the tire production is remarkable.

Six experts in collaboration with a tire company replied to a questionnaire. They first compared the impact of the tire in the 5 life-cycle phases considering the product environmental characteristics, lifecycle studies and expert perception (see Table 1). Then from the 118 available Eco-Design improvement

1 Many studies in literature are available. See the Rubber Manufactures Association website http://www.rma.org/scrap tires/scrap tires and the environment/ as reference starting point. 
areas of the general model, a specific list of 18 environmental issues is identified by a consensus meeting. In Table 2 the final AHP criteria and sub-criteria of the model are presented, evidencing the link among improvement areas and interested life-cycle phases.

Table 1. Weights of criteria for tire.

\begin{tabular}{|l|l|}
\hline Criteria & Weight \\
\hline Materials & 0.157 \\
\hline Production & 0.057 \\
\hline Transportation & 0.047 \\
\hline Use & 0.504 \\
\hline Disposal & 0.235 \\
\hline
\end{tabular}

Table 2. Selected environmental improvement areas: AHP criteria and sub-criteria.

\begin{tabular}{|c|c|c|c|c|c|c|}
\hline & ENVIRONMENTAL IMPROVEMENT AREAS (tire model) & 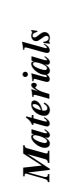 & 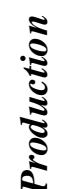 & 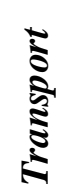 & $\frac{5}{5}$ & 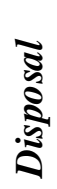 \\
\hline 1 & Use of materials with a view to their environmental performance & & & & & \\
\hline 2 & Prefer materials from renewable raw materials & & & & & \\
\hline 3 & Prefer recyclable materials & & & & & \\
\hline 4 & Avoid inseparable compos ite materials & & & & & \\
\hline 5 & Use energy efficient production technologies & & & & & \\
\hline 6 & Reduce energy consumption by optimum process design & & & & & \\
\hline 7 & Reuse materials contained in the product & & & & & \\
\hline 8 & Reduce material input for packaging & & & & & \\
\hline 9 & Increasing product durability & & & & & \\
\hline 10 & Indicate consumption of product along use stage & & & & & \\
\hline 11 & $\begin{array}{l}\text { Minimize energy consumption at use stage by increasing efficiency of } \\
\text { product }\end{array}$ & & & & & \\
\hline 12 & $\begin{array}{l}\text { Avoid and/or minimize environmental damage caused by emissions, } \\
\text { waste, noise, etc. at use stage }\end{array}$ & & & & & \\
\hline 13 & Create new or use existing collection system & & & & & \\
\hline 14 & Ensure high return rate & & & & & \\
\hline 15 & $\begin{array}{l}\text { Provide for over measure of material with a view to the reuse of } \\
\text { components }\end{array}$ & & & & & \\
\hline 16 & Make possible separation of materials for recycling & & & & & \\
\hline 17 & Ensure that materials are suitable for recycling & & & & & \\
\hline 18 & $\begin{array}{l}\text { Take into account end-user's opportunities for disposal and provide } \\
\text { for instructions for disposal }\end{array}$ & & & & & \\
\hline
\end{tabular}

The available improvements that the producer wants to compare are seven:

1.

Corn. A biologic tire with corn polymer can substitute standard materials of lampblack in the mixture. Such improvement reduces environmental impact by adopting materials derived from renewable energy sources and allowing an easier disposal.

2.

Silica. Silica could be mixed in the tread to reduce rolling resistance. 
3.

Modularization and integration of production. Through a modular integrated robotized system, production phases are reduced with a shift from job shop to flow shop plant organization. Energy consumption and packaging decrease due to reduction of inbound transportation.

4 .

Re-tread. Manufacturers and retailers can set policies on return, re-tread and replacement to reduce the waste generated from tires and increase their lifespan.

5 .

Regeneration. Used pneumatic is regenerated considering its market demand. An interesting way to provide a sustainable destination for post- consumer elastomers is to mix them with olefinic thermoplastics, which represents a type of recycling. Generally, researchers use post-consumer ground tire rubber, named recycled rubber [17].

6.

Production of $R D F$. Tires can be disposed by producing refuse derived fuel (RDF) mixing it with municipal solid wastes so to increase their heating value (LHV). Tires, when burned, produce the same amount of energy as oil, 25-50\% more energy than coal, and 100200\% more energy than wood, according to the U.S. Environmental Protection Agency.

7. Direct usage as fuel. The tires' high heating value makes scrap tires a good alternative fuel for industries with energy-intensive processes, e.g. cement plants, electricity-generating facilities, pulp and paper mills.

Table 3. Overall synthesized priorities for the alternatives.

\begin{tabular}{|l|c|c|c|}
\hline \multicolumn{1}{|c|}{ Name } & Ideals & Normals & Raw \\
\hline Silica & 1,000 & 0,359 & 0,120 \\
\hline Regeneration & 0,473 & 0,170 & 0,057 \\
\hline Corn & 0,418 & 0,150 & 0,050 \\
\hline Direct usage as fuel & 0,231 & 0,083 & 0,028 \\
\hline Production of RDF & 0,230 & 0,083 & 0,028 \\
\hline Modularization and integration & 0,221 & 0,080 & 0,027 \\
\hline Re-tread & 0,209 & 0,075 & 0,025 \\
\hline
\end{tabular}

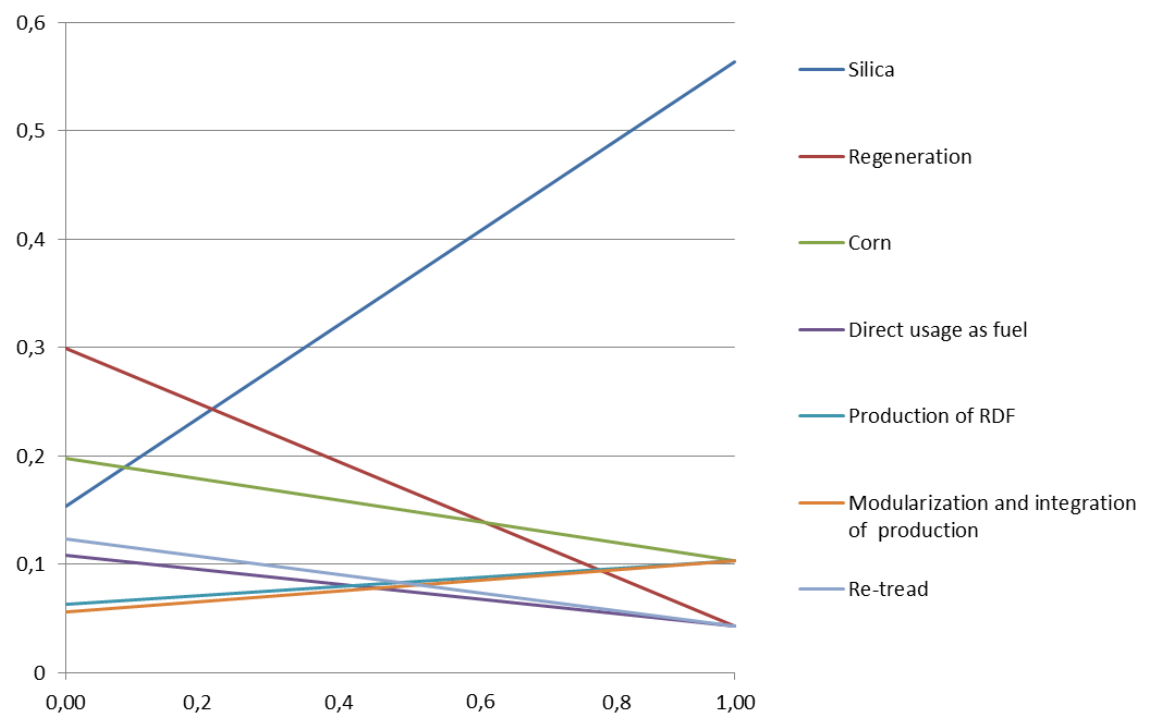

Figure 2. Sensitivity analysis on "Use intensive" criteria.

Results in Table 3 show that working on raw materials is to prefer and that, contrarily to what is usually done, energy production from tires is not a top priority improvement. This is coherent with the negative 
environmental impact of those solutions on the community. In particular, a sensitivity analysis was also conducted on the most important life-cycle phase to study effect of weights of criteria and sub-criteria (Figure 2). The analysis shows that there are some relationship of dominance (Regeneration on Direct usage as fuel and Re-tread; Corn on Production of RDF and Modularization and integration of production) that can support the decisional process, reducing the number of possible alternatives and better guiding designers to the most preferable intervention of improvement.

\section{REFERENCES}

[1] Braungarta M., McDonough W., Bollinger A. (2007). Cradle-to-cradle design: creating healthy emissions - a strategy for eco-effective product and system design, Journal of Cleaner Production, 15, $1337-1348$.

[2] Jeswiet J., Hauschild M. (2005). EcoDesign and future environmental impacts, Materials and Design, 26, 629-634.

[3] Hertwich E.G. (2005). Life Cycle Approaches to Sustainable Consumption: A Critical Review, Environmental Science \& Technology, 39/13, 4673-4684.

[4] Baumann H., Boons F., Bragd A. (2002). Mapping the green product development field: engineering, policy and business perspectives, Journal of Cleaner Production, 10/5, 409-425.

[5] Kimura F. (1999). Life Cycle Design for Inverse Manufacturing, Proceedings of EcoDesign 99, Tokyo, 995-999.

[6] Schischke K., Hagelüken M., Steffenhagen G. (2005). An Introduction to Ecodesign Strategies: why, what and how, Fraunhofer IZM, Berlin, http://www.ecodesignarc.info/ .

[7] Ng Eddie C.Y., Chuah K.B. (2010). Evaluation of Eco Design Alternatives using Fuzzy AHP Methodology, Proc. Design Conference 2010, Chicago, USA, January 2010.

[8] Kengpol A., Boonkanit, P. (2010). The decision support framework for developing Ecodesign at conceptual phase based upon ISO/TR14062. International Journal of Production Economics, doi:10.1016/j.ijpe.2010.10.006.

[9] Kengpol A., Boonkanit, P. (2010). The Development and Application of a Decision Support Methodology for Product Eco-Design: A Study of Engineering Firms in Thailand. International Journal of Management, 27/1 APR 2010.

[10] Borchardt M., Pereira G. M., Sellitto M. A. (2009). The assessment of ecodesign applications using the Analytic Hierarchy Process: a case study in three furniture companies, $12^{\text {th }}$ Int. Conference on process integration, modelling and optimisation for energy saving and pollution redution. 10-13 may 2009, Rome.

[12] Gonzales J., Sakundarini N., Ariffin R., Taha Z.b. (2010). Integrated Eco-Design Tool for Malaysian Automobile Industry, Journal of Advanced Computational Intelligence and Intelligent Informatics, 14/1.

[13] Jozi S.A., Irankhahi M. (2010). Environmental Risk Assessment of Gas pipelines by using of AHP Combined method, Journal of Environmental Studies, 36/53.

[14] Wimmer W., Züst R. (2002). ECODESIGN PILOT, Product-Investigation, Learning- and Optimization-Tool for sustainable product development, with CD-ROM. Dordrecht, The Netherlands: Kluwer Academic Publishers.

[15] Ozawa Y., Akutagawa K., Yanagisawa K., Hirata Y., (2004), Ecology-Friendly Materials Technologies in Tire, Journal of the Society of Rubber Industry, Japan, 77/6, 219-225.

[16] EPA - Environmental Protection Agency, (2006). Scrap Tire Cleanup Guidebook, A Resource for Solid Waste Managers Across the United States. EPA Publications.

[17] Da Silva, Luciana P. , Rocha, Jairo S. , Pacheco, Elen B. V. , de, Thiago A. , Bouças, O. and Furtado, Cristina R. G.(2008) 'Mechanical and Morphological Properties of Polypropylene and Regenerated TireRubber Blends', International Journal of Polymeric Materials, 57: 6, 555-68. 